\title{
El Proyecto de Normalización Documental de Museos: reflexiones y perspectivas
}

\author{
Andrés Carretero Pérez \\ Subdirector \\ Museo Nacional de Antropología
}

\section{Resumen}

Domus es una aplicación informática de gestión museográfica desarrollada por el Proyecto de Normalización Documental de Museos del Ministerio de Cultura, que abarca tanto la gestión de los bienes culturales como los aspectos más generales de las tareas administrativas de los centros. El texto realiza una breve presentación de la misma, tratando de resaltar sus metas de unificación de procesos técnicos de trabajo, intercambio de información y apertura al exterior de las instituciones museísticas.

\section{Palabras clave}

Museos / Documentación / Informatización

\section{Introducción}

Cuando hablamos del museo del futuro, del museo vivo e interactivo, por usar algunos de los términos de moda, pensamos sobre todo en la utilización de las nuevas tecnologías, en la digitalización de imágenes, en la elaboración de productos multimedia, y en la difusión de los museos y sus actividades en Internet.

Cierto. Si las exposiciones y la atracción de públicos cada vez más amplios son parte consustancial del museo, en las nuevas tecnologías está buena parte del futuro de nuestras instituciones. Incluso museos pequeños o situados en lugares alejados, fuera de las rutas turísticas, podrán dar a conocer sus colecciones y sus actividades con mayor facilidad, y podrán entrar en un circuito de "museos virtuales" que les dará mayores oportunidades para desarrollar su tarea cultural y para sobrevivir económicamente.

Sin embargo, cuando pensamos en este futuro tecnológico, que a todos se nos viene encima, olvidamos con demasiada frecuencia que la base para que las tecnologías informáticas sean útiles y eficaces está en que los museos formen parte de una red, controlen su información, unifiquen los procesos de trabajo, compartan los modelos descriptivos, homologuen los lenguajes empleados en la catalogación y la gestión, etc.

\section{De las particularidades de cada museo y su historia}

Es casi inevitable comenzar cualquier reflexión sobre museos señalando que las instituciones museísticas son variadas y polifacéticas, y tienen una historia larga y diversa; frases cuya traducción más directa sería "no esperen normas generales de funcionamiento en los museos; predominan las excepciones y los casos particulares; cada museo tiene su propia idiosincrasia".

Así es, en efecto. Las razones son de varios tipos, pero entre ellas podemos destacar cuatro básicas:

En primer lugar, la historia de los museos, la historia de cada tipo de museo, está muy unida a las disciplinas científicas que sustentan su temática o su metodología de análisis de las colecciones. Los museos de Ciencias Naturales surgieron por el interés (y con el apoyo de) zoólogos y botánicos, los arqueológicos de la mano de los anticuarios y arqueólogos, y los de bellas artes amparados por los académicos, historiadores y críticos del arte.

La consecuencia inmediata fue que los museos tendieron a considerarse como una ramificación, como una derivación, de cada campo académico. La orga- 


\author{
Mientras el trabajo documental museistico ha tenido un \\ carácter manual, el problema de la diversidad de prócticas ha \\ sido sólo una molestia, pero cuando los ordenadores han \\ comenzado a pedirnos consistencia para registrar la \\ información, y para intercambiarla a través de las redes \\ informáticas, nuestra descoordinación ha resultado más que \\ patente
}

nización, los tipos de estudio, la metodología de análisis, y los propios criterios de selección de bienes culturales y de reunión de documentación, derivaban de los intereses y las perspectivas particulares de cada disciplina. Todavía hoy son visibles con claridad estas diferencias de criterio.

En segundo lugar, aunque la ya tradicional definición de museo del ICOM señale como funciones básicas la recogida, conservación, investigación y divulgación de sus colecciones, de forma inevitable se produce un predominio de unas sobre otras funciones. La conservación, y sobre todo la investigación, han sido las funciones primordiales de los museos durante mucho tiempo, pero una investigación sobre las colecciones vista desde el campo académico, como una interpretación científica de la materia.

Sólo en los últimos años ha comenzado a aumentar de importancia, e incluso a predominar, la difusión, lo que ha puesto al descubierto no pocos problemas: transmitir al público los contenidos del museo exige una traducción de los contenidos científicos de los estudios realizados $y$, sobre todo, exige un replanteamiento de la relación entre los intereses del colectivo científico y los intereses del público general, es decir, de los públicos no especializados, respecto a las colecciones o la temática del museo, tarea para la que las disciplinas científicas (y en consecuencia los museos a ellos asociadas) están muy desigualmente preparadas.

En tercer lugar, en estrecha relación con los puntos anteriores, descubrimos que esa diversidad de museos encierra también la carencia de una idea general de servicio público. Al margen de una exposición más o menos atractiva o críptica en su estructura y contenidos, el visitante nunca sabe qué tipo de información y servicios podrá obtener en cada museo.

A este respecto es significativa la diferenciación entre visitante, utilizada comúnmente en los museos, y usuario, utilizada en bibliotecas o archivos. El público usa las bibliotecas y archivos, instituciones modela- das para prestarle un servicio, de una forma participativa y acorde a sus intereses; en cambio visita los museos como si fuera un invitado en casa ajena.

Y en cuarto lugar, la diversidad de las colecciones, o para ser más exactos la individualización de los elementos que componen las colecciones que guardan los museos, a diferencia del carácter seriado y repetitivo que predomina, por ejemplo, en el mundo bibliotecario, ha hecho parecer innecesario (económicamente despreciable) cualquier intento de unificación de normas catalográficas, etc. Frente a la realidad de que cada ejemplar de una edición de Platero y yo va a necesitar exactamente los mismos elementos catalográficos en cualquiera de las mil bibliotecas en las que ingresen, por lo que una catalogación normalizada puede ahorrar el trabajo de 999 catalogadores, dos cuadros de Goya, e incluso una serie de ánforas romanas o de bifaces paleolíticos, dentro de su relativa similitud, nunca van a tener exactamente el mismo contenido catalográfico.

A partir de estas consideraciones va resultando comprensible por qué cada institución tiene su propia idiosincrasia; por qué los procesos de trabajo interno son diversos; por qué no existe unidad ni criterios genéricos, más allá de los que (algunas veces) impone la lógica, en las normas de catalogación; y por qué nunca se ha planteado seriamente la regulación técnica y administrativa de la actividad museística.

Mientras el trabajo documental museístico ha tenido un carácter manual, este problema de la diversidad de prácticas ha sido sólo una molestia, pero cuando las máquinas se han ido introduciendo en nuestra vida, cuando los ordenadores han comenzado a pedirnos consistencia para registrar la información, y para intercambiarla a través de las redes informáticas, nuestra descoordinación ha resultado más que patente.

Y muchos de los intentos de informatización de la gestión, o simplemente de la catalogación de las colecciones, de los museos han fracasado o resultan 
difícilmente extensibles a instituciones ajenas: Cuando un museo ha iniciado la automatización de su gestión, a falta de análisis claros de los procesos de trabajo, ha informatizado tanto las etapas lógicas y necesarias de la gestión como las manías de la institución, aquellos hábitos de control de la gestión surgidos seguramente de los avatares particulares de su historia, o de las peculiaridades de su organización interna, o de prácticas administrativas ancestrales, o del peso de un director carismático que impuso determinadas pautas de actuación ante los préstamos de obras o cualquier otra cuestión; hábitos cuya historia a menudo desconocemos, pero tan firmemente arraigados que se dan por supuestos y cuya explicación evidente es: "Aquí ésto siempre se ha hecho asî". Aquí sí, pero no en los museos vecinos, que tienen a su vez sus propias manías y no están dispuestos a cambiarlas.

Y en esta diversidad de prácticas tiene un lugar central la disparidad de estructuras catalográficas, la multiplicidad de las fichas, problema que preocupa en todas partes, porque el ámbito de los museos es tan diverso, como señalábamos al comienzo, y dentro de cada especialidad hay tantas formas de concebir la descripción y el estudio científico de los fondos museográficos, que en cada país podemos encontrar cientos de modelos de fichas diferentes, incluso entre las diversas secciones de una misma institución; y problema duro de resolver porque se producen aún muchas reticencias entre los especialistas a perder la especificidad de su campo de estudio en aras de una uniformidad descriptiva que seguramente no es la suya, y que a muchos les parece un empobrecimiento. Una herencia directa, un fruto de la histórica consideración de los bienes culturales que guardan los museos desde el punto de vista científico, desde el punto de vista del especialista científico para ser más exactos, que ha ido incorporando elementos, epígrafes descriptivos o simplemente distintas denominaciones de los atributos según las normas o tradiciones de cada disciplina, que ha pensado la catalogación de los bienes culturales como un dispositivo de comunicación entre eruditos y estudiosos, y no desde el punto de vista global del Patrimonio Cultural y del servicio público general que implica la descripción unitaria y la difusión de los contenidos del museo.

\section{Del Proyecto de Normalización Documental}

De la meditación sobre estas y parecidas cuestiones, en 1993 se inició el trabajo de un voluntarioso grupo de técnicos de la entonces denominada Dirección de los Museos Estatales del Ministerio de Cultura con la finalidad de hacer frente a ese aparente caos y "sistematizar normas documentales, tanto en lo relativo a la catalogación y tratamiento técnicoadministrativo de los fondos museográficos, como al establecimiento de terminologías para la clasificación, denominación y descripción de diversos tipos de items" (Carretero y otros, 1996: xiii).
Al año siguiente la tarea consiguió un cierto reconocimiento oficial, y por Resolución de la Dirección General de Bellas Artes y Bienes Culturales de 25 de octubre de 1994 el grupo se constituyó en Comisión de Normalización Documental de los Museos Estatales con el encargo de "definir y unificar los procesos documentales museográficos y administrativos, la normalización de terminologías y el desarrollo de su aplicación informática".

Los fines de la Comisión eran múltiples y ambiciosos:

En primer lugar, interesaba definir un mínimo común denominador para la actividad técnica de los museos, analizando los procesos de trabajo, los flujos de actividad interna del Museo, y tratando de establecer las gestiones, etapas y controles necesarios, dictados por cuestiones técnicas o legales-administrativas, y que en principio deberían ser cuasi-similares en cualquier tipo de museo, al margen de su temática, tamaño o dependencia administrativa.

En segundo lugar, se trataba de unificar los elementos descriptivos y clasificatorios necesarios para el inventario y catalogación de los bienes culturales que componen las colecciones de los museos; intentando superar los intereses disciplinarios o académicos.

En tercer lugar, se quería remarcar el hecho de que un museo guarda también fondos documentales, fondos bibliográficos, etc., y no sólo fondos museográficos, colecciones, objetos (que en todo caso tienen el sentido de documentos culturales), y que el conjunto define un sistema documental particular, diferente del archivo, la biblioteca o la "colección" en sentido tradicional.

En cuarto lugar, resultaba evidente la necesidad de iniciar el proceso de estructuración y unificación de la terminología empleada en la descripción y clasificación de los documentos conservados en los museos, tarea para la que se constituyeron los Grupos de Vocabularios Técnicos de los que hablaremos más adelante.

Y en quinto y último lugar, con el ánimo de facilitar el trabajo cotidiano, la tarea incluía la propuesta de desarrollo de una aplicación informática que recogiera las conclusiones de las etapas anteriores, ayudara en la gestión interna de los centros, y facilitara el anhelado intercambio de información.

Después de más de dos años de intensa actividad, en la que junto al trabajo continuo del propio equipo se hicieron consultas a un buen número de instituciones y de técnicos sobre su práctica y su experiencia, la Comisión presentó el informe titulado Normalización documental de museos: elementos para una aplicación informática de gestión museográfica, cariñosamente apodado Mutocho por su volumen y aridez.

Extensión y aridez, en efecto, eran dos de sus características primordiales, porque el informe no se planteaba como un texto de divulgación o un manual para la evangelización de los descreídos de la documentación 
museológica, sino como un análisis funcional, sistemático (y mecánico en ocasiones), para que los técnicos informáticos, más que los de museos, supieran cómo atacar la automatización de las tareas museísticas. Sin embargo, no eran las únicas. Cuando la Subdirección General de los Museos Estatales decidió publicar el informe (cuestión no prevista durante el proceso de elaboración), para nuestra sorpresa, la edición se agotó en el primer año, y la reedición que la siguió lleva el mismo camino. La elaboración del análisis funcional nos había conducido a reflexiones, a veces básicas, sobre los principios de nuestro trabajo museístico, que sí han interesado a los museólogos, incluso a aquellos que no están de acuerdo con nuestras conclusiones. Y paralelamente la rápida evolución de la realidad en que vivimos ha hecho que muchos técnicos que en 1993 no consideraron el interés de la tarea emprendida hayan ido apreciando su necesidad a lo largo de los años siguientes. Por una u otra razón, aunque a los autores nos guste pensar que hemos tenido algo que ver, hoy es perceptible el cambio de actitud, el interés de la comunidad museística por estas tareas áridas, pero necesarias, de la "documentación".

El informe continuó, por lo demás, su camino previsto y sirvió de base, de "pliego de prescripciones técnicas", para el desarrollo de la aplicación de gestión museográfica que reza el subtítulo, tarea cuya realización se adjudicó a una empresa informática, mediante concurso público, etc., etc. Quizás sea preferible, en esta breve historia del proyecto, pasar con rapidez por las incidencias del período que sigue: desarrollos informáticos que no se adecuan a las necesidades y deben rehacerse ...; escasez presupuestaria y lentitud de las tramitaciones administrati- vas, ...; descubrimiento de nuevas posibilidades, y también de limitaciones e imposibilidades informáticas, ...; expectativas de muchos museos en parte frustradas por los continuos retrasos, ... No vamos a esforzarnos en explicar porqué una tarea que debía estar terminada a comienzos de 1997 no lo estuvo hasta comienzos de 1999, necesitó todo ese año, y 2000, para pruebas de prototipos y corrección de detalles, y no ha comenzado a implantarse de manera sistemática en los museos hasta 2001 .

\section{Ya tiene nombre: Domus}

El resultado de estas peripecias es la versión 1.0 de una aplicación informática que ha recibido, de modo casi accidental, el nombre de Domus (proveniente del apócope Documentación de Museos más que del domus latino), y que pretende cubrir una amplia variedad de tareas dentro de la gestión museográfica.

Sin ánimo de exhaustividad, ni en las explicaciones que siguen ni en las ilustraciones que reproducen algunas de las pantallas, Domus abarca tanto el control de la información sobre los fondos museográficos y documentales del Museo, como sus procesos de ingreso, y las gestiones de que son objeto (documentación gráfica, tratamientos de conservación y restauración, movimientos a exposiciones, estudio, etc), permitiendo la automatización de algunos elementos como la asignación de números de inventario, la generación de actas, listados, escritos y formularios varios, etc., y se ocupa igualmente de la gestión administrativa básica del centro.

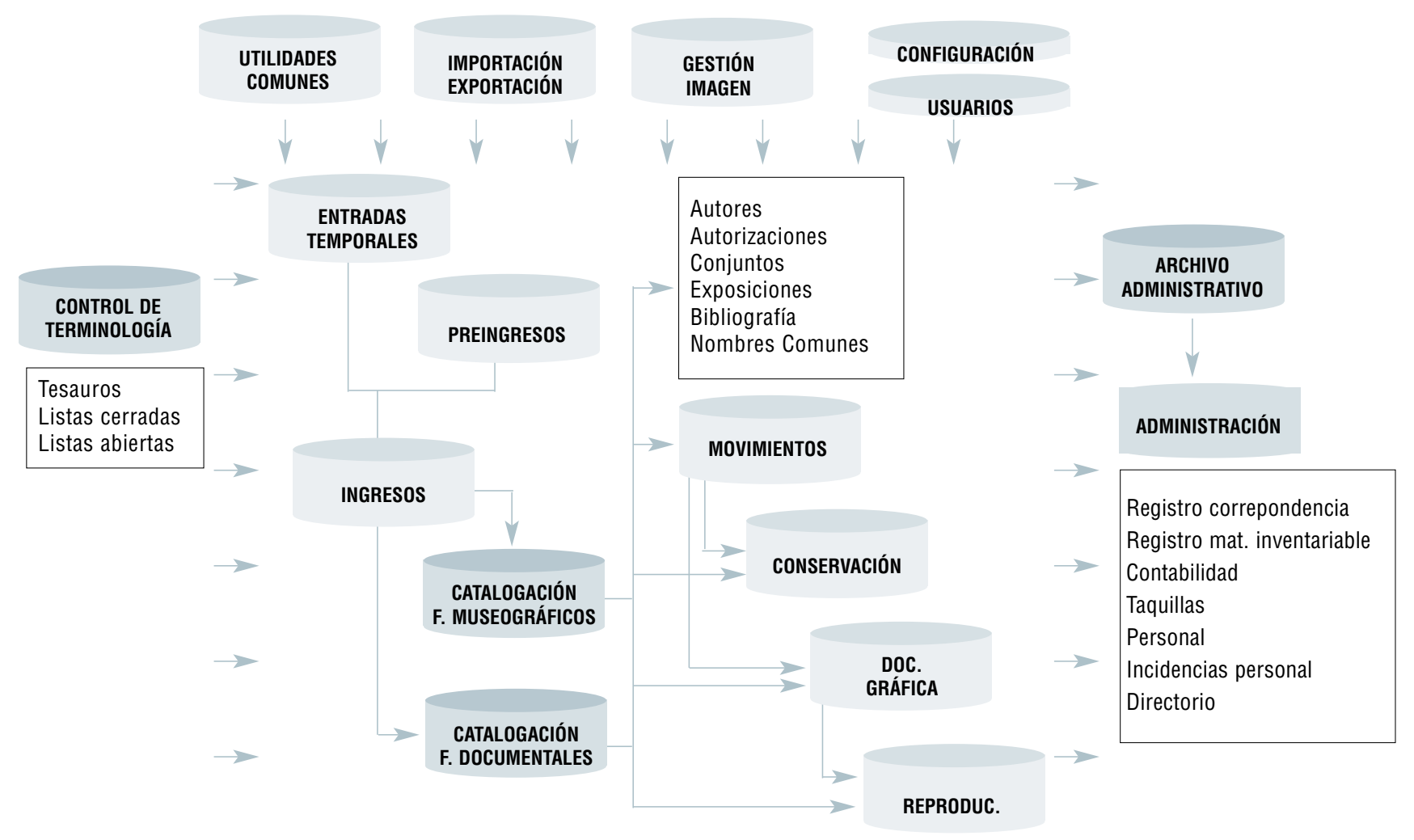


I) El Área de Fondos tiene cuatro módulos básicos: Catalogación, Procesos, Información relacionada y Consulta.

Ia) El módulo de Catalogación incluye las tablas y pantallas de introducción de datos para la descripción y clasificación de Fondos Museográficos y Fondos Documentales.

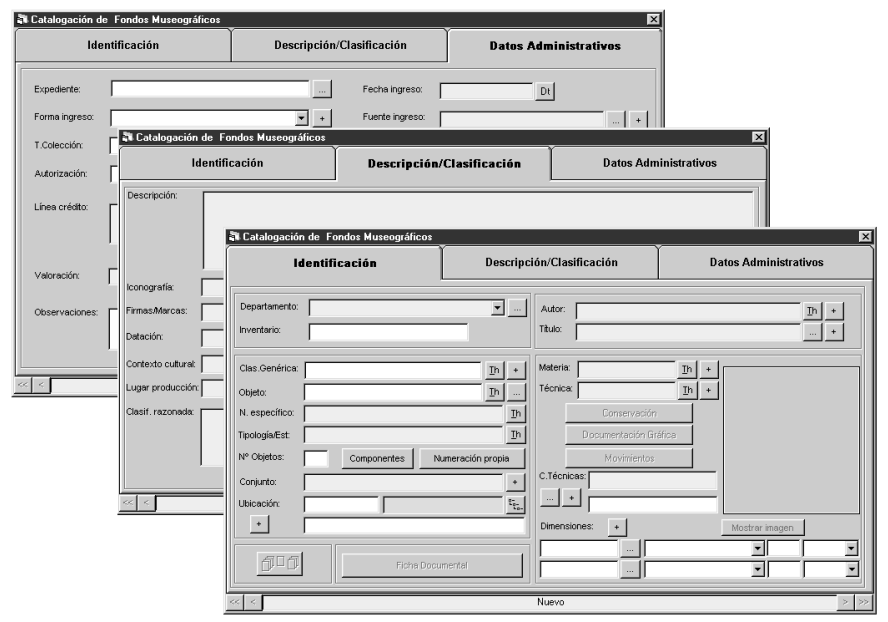

La estructuración de las bases de datos de catalogación fue sin duda la labor más larga, tediosa y "consensuada", ya que no sólo se consultaron fuentes documentales, y modelos descriptivos de diversas instituciones, sino que se mantuvieron además reuniones y se realizaron consultas a numerosos técnicos. En el ánimo de la inclusión, para dar cabida a las particularidades y la casuística de muy diversos tipos de bienes, la estructura resulta extensa en una primera apreciación (47 categorías con 142 unidades de información, muchas de ellas conectadas con tablas de estructura más amplia y/o repetibles en caso necesario), aunque pronto la práctica muestra que los epígrafes a cumplimentar no son muchos más que en las tradicionales fichas manuales.

Cuestión operativa diferente es la inexistencia (en el presente estado de desarrollo) de formatos de pantalla simplificados, a modo de inventario, que pueden parecer aconsejables para muchos museos que tienen un mínimo o nulo control documental de sus colecciones. Sin embargo, se trata de una opción intencional y meditada: el actual formato de pantalla de catalogación, aún para la consignación de un mínimo número de epígrafes, obliga a la visualización de la mayor parte de la estructura. La reflexión es que si se dispone de la información para esos epígrafes se consignará al mismo tiempo que los mínimos imprescindibles, cosa que no sucedería con una pantalla simplificada con unos pocos datos básicos. La idea de que una vez inventariado a un nivel elemental todo el museo volveremos sobre los registros para completar la catalogación .... es fiar mucha tarea al futuro. En particular en los museos con menos dotación de personal es imprevisible en qué momento podrá completarse la información que no se cumplimente en el proceso de instalación del sistema.
Otra de las características básicas de la estructura de catalogación, también intencionada y que endurece su utilización, es el gran número de controles terminológicos: todos aquellos epígrafes básicos para la descripción y clasificación de los bienes culturales, y a través de los cuales se plantea la recuperación sistemática de la información están controlados por listas abiertas, listas cerradas y tesauros. Salvo en los campos de texto libre y los controlados por listas abiertas (que son los menos) no pueden consignarse términos o expresiones que no estén previamente controlados. La finalidad es evidente: evitar que la escritura natural de cada catalogador o investigador reproduzca la falta de rigor y las descripciones y clasificaciones personalistas que en muchas ocasiones encontramos en las fichas manuales (y que trasladamos inevitablemente a las bases de datos). Primero en cada centro, y después en una tarea interinstitucional, por este camino iremos, indudablemente, unificando nuestra terminología descriptiva y clasificatoria.

Por otra parte, somos conscientes de que esta estructura catalográfica no es definitiva ni permanente, y que de hecho no durará demasiado tiempo en su estado actual. Con seguridad, cuando se extienda su uso, los catalogadores irán sugiriendo modificaciones y ampliaciones; pero sobre todo la perspectiva en un futuro a medio plazo es que se subsuma, se integre en estándares más genéricos. En su momento observamos con cierta satisfacción que la estructura desarrollada se asemejaba en muchos aspectos a las planteadas por otros proyectos internacionales paralelos (por ejemplo, Grant, 1994; GETTY ART HISTORY ..., 1995; CIDOC, 1995). La consecuencia lógica de las semejanzas es la tendencia a la unificación, y ya existen organismos centrados en la tarea, como el CIMI (Consortium for Interchange of Museum Information) [http://www.cimi.org/] y sobre todo el EMIII (European Museum Information Institute) [http://www.emii.org/] volcados en el desarrollo de un standard, de un formato MARC museístico, por así llamarle, ahora al amparo de los nuevos lenguajes de la red como el XML (eXtensible Markup Language).

Ib) La subárea de Procesos incluye los módulos necesarios para controlar los trámites de gestión más habituales de los fondos museográficos y documentales: preingreso e ingreso, entradas temporales, movimientos (internos y externos), documentación gráfica y conservación.

La gestión de preingresos (gestiones relativas a las "ofertas de ingreso") e ingresos propiamente dichos parece tener un interés muy relativo, al menos para los museos con muy pequeño volumen de nuevas entradas en las colecciones, pero tiene ventajas de gestión como la multiplicación automática de registros para los objetos con la información común al expediente administrativo, la asignación de números de inventario, la generación de actas de recepción, certificados registrales, etc.

Menos dudas ofrece la utilidad, para cualquier tipo de museo, y al margen del volumen de actividad, de la 
gestión de las entradas temporales y de los movimientos de bienes culturales, que ayudan a controlar los objetos ajenos que llegan temporalmente a nuestra institución (sea para exposiciones, estudio, depósitos judiciales, ...), y los desplazamientos de nuestras propias colecciones, sea dentro del Museo (movimientos internos) o fuera (movimientos externos).

Seguramente el de Movimientos es el módulo de más compleja estructura interna ante la casuística de controlar múltiples bienes culturales que se desplazan a un mismo evento o por una misma causa, pero que pueden contar con diversas autorizaciones, distintas fechas de entrada y salida, diferentes transportes y correos, quizás sometidos a una exposición itinerante, ..., además de poseer elementos informativos propios (como valoración, condiciones particulares de exposición o manipulación, línea de crédito, ...).

Los módulos de Documentación gráfica y Conservación son sencillos en su funcionamiento y mantienen una constante vinculación con las bases de datos de Catalogación.

Aunque se trata de epígrafes tradicionales de las fichas de catalogación, se ha optado por eliminarlos como tales, estableciendo a cambio una interconexión permanente entre las bases de datos respectivas de modo que la información, íntegra, esté siempre accesible. La idea esencial es que cada documento gráfico de los bienes culturales, o cada informe, análisis o tratamiento de conservación/restauración, genere una anotación independiente, un registro propio, en su base de datos, en la que pueda describirse la acción con todo el detalle necesario, y que dicha información resulte accesible desde los demás módulos, de modo que obviemos la repetición de aquellos problemas de las fichas manuales con unos reducidos epígrafes de "Estado de conservación" y "Fotografía" que no permitían o dificultaban la consignación de actualizaciones, y reducían la información, en el mejor de los casos, a los tradicionales "Bueno", "Regular" o "Deficiente".

La estructura de ambas bases de datos es sencilla, pero es indudable que, sobre todo en el área de Conservación, los usuarios irán proponiendo mejoras.

Ic) El módulo de Información relacionada viene a ser un "área auxiliar" que incluye una serie de pequeños ficheros necesarios para consignar datos que suelen tener un uso muy repetido en catalogación y procesos de gestión:

- Datos biográficos de los Autores de los fondos del Museo.

- Descripción de las Autorizaciones administrativas emitidas con motivo de los ingresos, préstamos, exportaciones temporales, etc, de los fondos.

- Conjuntos museográficos y documentales formados por los objetos y/o documentos de las colecciones.
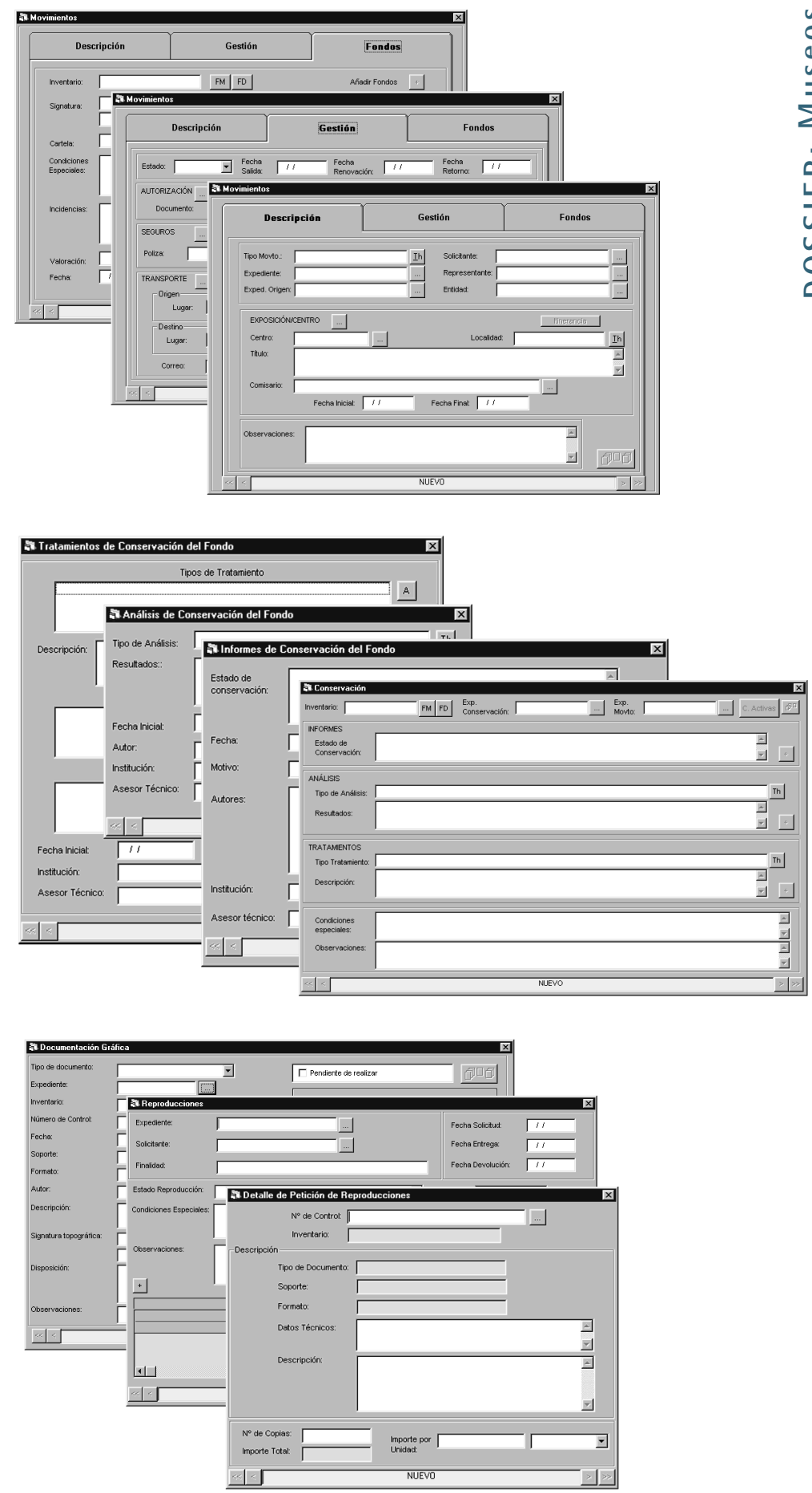

- Información sobre los titulares (en su caso) de Derechos de reproducción sobre determinados bienes culturales.

- Identificación de Exposiciones temporales, propias o ajenas, en las que han participado fondos de la institución.

- Referencia de las publicaciones (Fondos bibliográficos) en las que aparecen piezas de las colecciones.

- Tablas de vinculación entre los Nombres comunes utilizados para la denominación de los objetos con sus Nombres específicos y Tipologías para 
evitar confusiones o errores en la cumplimentación de los datos.

Id) El módulo de Consulta permite acceder a la base de datos documental BRS, en la que se realiza el volcado de toda la información del sistema, y a través de ella a la visualización/impresión/archivo de los datos en "modo texto". Es una potente herramienta de recuperación de la información, pero, por su elevado coste, se está estudiando su posible sustitución por otro
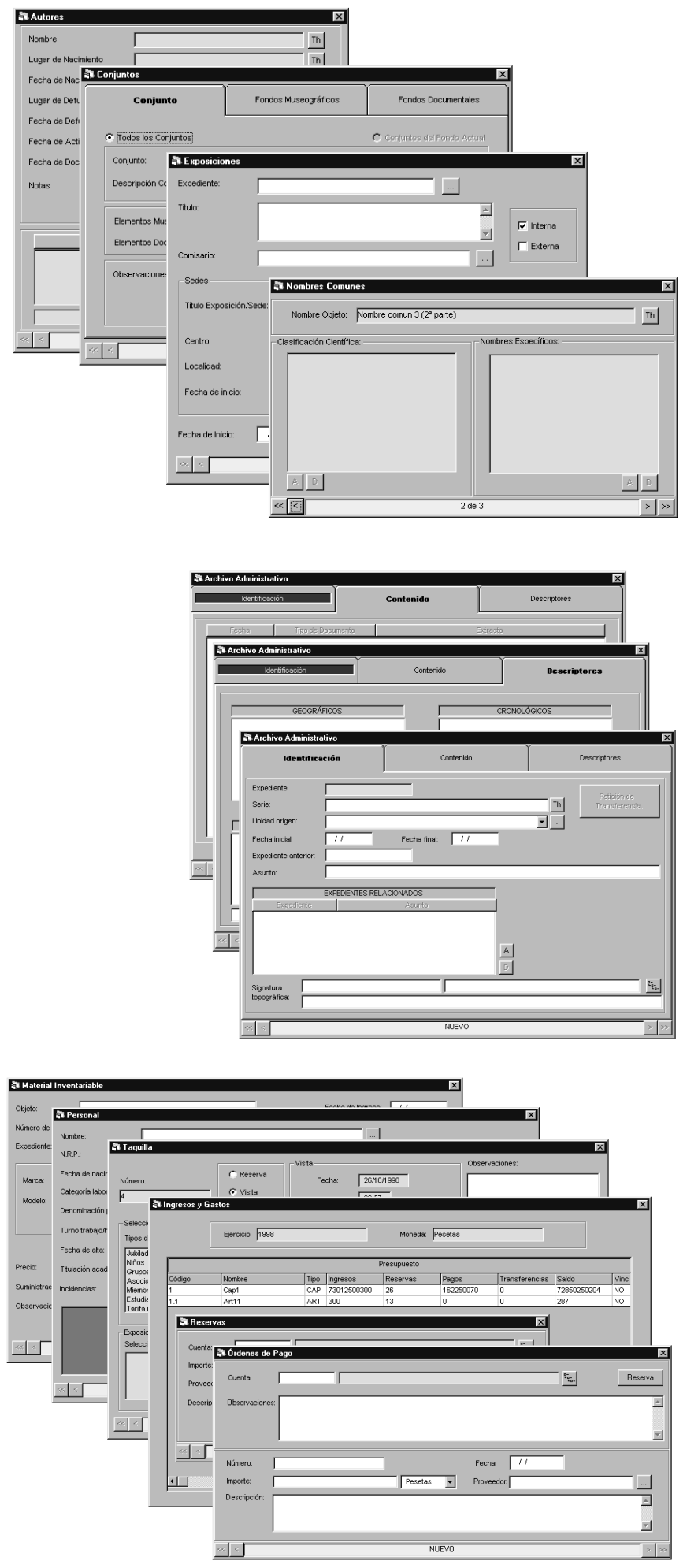

módulo que ofrezca prestaciones similares, o cercanas, a precios más asequibles para cualquier institución.

[Nota técnica: La duplicidad de gestores de datos de la aplicación (SQL Server 7.0 como gestor relacional y BRS 6.3 como gestor documental) se planteó en el inicio del desarrollo ante la previsión de enlazar la aplicación de gestión museográfica Domus con la aplicación de gestión bibliotecaria Absys, utilizada en la red de bibliotecas públicas y que trabaja sobre BRS, integrando ambas aplicaciones para la tarea museística. De este modo se obviaba el desarrollo del módulo de gestión bibliotecaria propio previsto en el proyecto, y se vinculaba a los museos a un standard de amplia implantación, lo que permitiría a las bibliotecas de los museos formar parte real de la red de bibliotecas públicas, acceder al Catálogo Colectivo, al programa Ariadna, etc.

Problemas técnicos que escapan a nuestro control han impedido esa interconexión entre Domus y Absys, lo que plantea dos consecuencias: una lamentable, la "amputación" de la aplicación, que ahora carece del módulo de gestión bibliotecaria previsto en el proyecto (cuestión que deberá solucionarse en un futuro próximo); y otra simplificadora: una vez que el papel del gestor documental ha quedado reducido a la estricta tarea de recuperación de la información "museística" sería factible el análisis de su sustitución o eliminación: el uso de BRS sólo resultará necesario en aquellas instituciones con un gran volumen de datos, en términos de millones de registros, que necesiten un gestor de tal potencia.]

2) El Área de Administración incluye algunos módulos de uso común al conjunto del sistema:

Archivo administrativo, que conecta con la práctica totalidad de los procesos de gestión permitiendo así, desde el inicio de los expedientes, un control eficaz de la documentación generada.

- Registro de Correspondencia, y en su caso de notas e informes internos.

- Directorio, que controla todos los nombres propios de personas e instituciones contenidos en el Sistema y otros de uso más particular por el personal de Administración, como

- Gestión de las solicitudes de Reproducciones fotográficas de los fondos, módulo vinculado tanto a la Contabilidad como a la base de datos de Documentación Gráfica

- Contabilidad o Control de gastos generales del Museo.

- Control del Personal y sus incidencias.

- Base de datos del Material inventariable de la institución.

- Gestión de Taquilla: generación de entradas de visitantes y control de ingresos.

- Gestión de la Tienda: control de existencias y facturación de ventas. 


\begin{tabular}{|c|c|c|}
\hline TESAUROS & LISTAS CERRADAS & LISTAS ABIERTAS \\
\hline Autores & Agrupación de colecciones & Actividades (Autores) \\
\hline Clasificaciones genéricas & Características técnicas & Descriptores onomásticos \\
\hline Contextos culturales & Categorías laborales & Estado de ingreso \\
\hline Iconografía & Colores & Hechos históricos \\
\hline Lugares geográficos & Datos técnicos & Lugares específicos \\
\hline Materias & Departamentos & Marcas \\
\hline Nombres comunes & Entidades bancarias & Productos químicos \\
\hline Nombres específicos & Estados de reproducción & Títulos \\
\hline Series documentales & Formas de ingreso & \\
\hline Técnicas & Formatos & \\
\hline Tipologías & Idiomas & \\
\hline Tipos de análisis & Ingresos extrapresupuestarios & \\
\hline Tipos de movimiento & Precisiones (Autores) & \\
\hline \multirow[t]{10}{*}{ Tipos de tratamiento } & Relación con el Museo & \\
\hline & Tipo de Colección & \\
\hline & Tipo correspondencia (Directorio) & \\
\hline & Tipo de documento (Fondos) & \\
\hline & Tipo de Incidencia (Personal) & \\
\hline & Tipo de medida & \\
\hline & Tipo documento administrativo & \\
\hline & Tipo documento correspondencia & \\
\hline & Unidades de medida & \\
\hline & Visitantes & \\
\hline
\end{tabular}

3) Y, por último, el Área de Sistema incluye diversos módulos de configuración y de control terminológico que en principio sólo serán accesibles a los administradores del sistema informático:

- Tesauros, Listas cerradas, y Listas abiertas, módulo de control terminológico en el que se consignan los términos autorizados para la consignación de la información pertinente en los diversos procesos. Las tablas hasta el momento desarrolladas son las siguientes:

- Signaturas topográficas, módulo que permite generar una tabla jerarquizada con la estructura física de nuestro museo, y sobre ella una descripción específica, y tan detallada como se quiera, de las posiciones en que se guardan los bienes culturales.

- Control de usuarios, módulo que permite la creación de grupos de usuarios con diferentes niveles de acceso, y la asignación de contraseñas individuales y plazos de utilización a personal técnico, investigadores, etc.

- Datos Directorlinstitución, para la emisión de formatos impresos, etc.

- Cambio de numeración, pequeña utilidad que permite añadir ceros a la izquierda al conjunto de los inventarios cuando una colección pasa de dos a tres dígitos, de tres a cuatro, ..., es decir, cuando nuestra colección pasa de 999 objetos a 1000, de 9999 a 10000 , etc., para mantener la ordenación secuencial en listados, etc.

- Importación/exportación: Suplementando este módulo de Sistema se encuentran actualmente en desarrollo ejecutables independientes para la importación y exportación de datos a las diversas bases de datos, tesauros y listas, así como un gestor de la integración de imágenes digitales.

\section{Perspectivas del proyecto}

El actual Domus es sólo el inicio, la primera parte, del desarrollo informático que preveía el Proyecto de Normalización Documental, y en un futuro próximo, dentro de la plena compatibilidad con los esquemas actuales, se producirán innovaciones y mejoras significativas, tanto técnicas como en la "lógica" del sistema.

En el momento presente son detectables cuatro áreas de evolución paralelas:

- Desarrollo informático

- Implantación en museos

- Volcado de información

- Normalización y unificación terminológica

Una aplicación informática nunca es un producto acabado; antes de haberse concluido muchos de sus aspectos técnicos resultan ya obsoletos, y a cada paso de la programación, la reflexión lleva a imaginar nuevas funcionalidades. Durante el propio desarrollo de la aplicación han podido detectarse problemas y funcionalidades no previstas en el proyecto inicial, y se han planteado modificaciones para mejorar el funcionamiento general del sistema y su mayor adaptabilidad a cada centro particular.

Del mismo modo, a medida que aumente el número de usuarios surgirán propuestas para aumentar y mejorar las funcionalidades y hacer más cómodo el 
manejo de la aplicación, sugerencias que desembocarán en una "versión 2" y sucesivas.

Por otra parte, el proyecto inicial contemplaba tanto la gestión textual de la información como la gestión de imágenes. Para facilitar la claridad de la ejecución de la tarea (y evitar que el atractivo de las imágenes digitales en pantalla crearan la ilusión de que "ya estaba todo hecho") se optó por contratar en primer lugar la gestión documental textual de la información. Una vez completada esta etapa, resulta necesario iniciar el diseño y desarrollo, mucho más simple, de los elementos de conexión y control de coherencia de la información entre la aplicación, el software de gestión de imagen que se determine y los sistemas de captación (escáneres, cámaras digitales, ...) y almacenamiento (discos ópticos, CD-ROM, DVD, ...).

E igualmente resulta ahora necesario acometer la conexión en red de los museos, con tres facetas cuyo desarrollo relativo, unificado o independiente, dependerá de las decisiones que se tomen respecto a la difusión de la información que conservan las instituciones y a las funciones que se quiera adjudicar a las comunicaciones externas:

En primer lugar los museos deben conectarse entre sí,

a) en lo relativo a la consulta y utilización de los datos de las respectivas bases de datos de catalogación (para lo cual puede plantearse un "catálogo colectivo"),

b) pero también para compartir, intercambiar y actualizar ficheros de autoridades y terminología: imaginemos que periódicamente todos los museos que utilicen el sistema remiten a los responsables técnicos que se establezcan los índices de los diversos campos de catalogación, y que tras la revisión y unificación pertinentes se nos devuelven, de forma automática, los índices o tesauros actualizados y se modifican los datos pertinentes en nuestras bases de datos ....

c) y, por qué no, para otros aspectos de gestión de las colecciones: sigamos imaginando que podamos grabar en el sistema de nuestros partenaires los datos sobre la exposición temporal que deseamos realizar y generar expedientes de solicitud de préstamo con los datos de los objetos que nos interesan.

En segundo lugar, es previsible que los museos se conecten, con las mismas funcionalidades u otras distintas, con sus respectivos servicios centrales administrativos, desde los cuales se podrán grabar en el sistema de cada centro las autorizaciones de ingreso o préstamo de colecciones, los presupuestos anuales o las modificaciones pertinentes, las aprobaciones de gasto, etc.

Y, en tercer lugar, frente a las anteriores conexiones, de carácter estrictamente técnico, los museos deberán "conectarse" a las redes externas de difusión, de uso general: deberán abrir sus páginas a los usuarios de Internet con el volumen de información y las funcionalidades que se establezcan en cada caso.

En cuanto a la implantación de la aplicación en los museos, es lógico que las instalaciones hayan comenzado por los museos dependientes de la Subdirección General de los Museos Estatales, en cuyo seno se ha desarrollado, pero la meta del proyecto es lograr la máxima extensión en el uso de la aplicación para lograr la "normalización documental" del mayor número de museos, al margen de titularidades administrativas.

Según el pliego de condiciones técnicas del contrato de desarrollo, la aplicación es propiedad exclusiva del Ministerio de Educación, Cultura y Deportes, por lo que no existe ningún problema para que, de forma gratuita o con las fórmulas administrativas o económicas que se establezcan, el Ministerio distribuya copias o licencias de uso de la aplicación a los museos que estén interesados.

Las instancias administrativas deberán decidir el ritmo, orden y criterios de extensión de la aplicación al resto de los museos gestionados por el propio Ministerio y a los gestionados por otros Ministerios; a los museos de titularidad estatal gestionados por las Comunidades Autónomas; y a los museos de otras titularidades, sean públicos o privados, ya que museos de todas estas diversas categorías se han mostrado interesados por el uso de la aplicación. La extensión de las implantaciones a los numerosos museos de países hispanoamericanos igualmente interesados en el proyecto deberá estudiarse con detenimiento y requerirá, con toda seguridad, la colaboración de terceros para ser económicamente viable.

Es previsible que la cesión de derechos de uso de la aplicación a museos que no sean competencia exclusiva del Ministerio de Educación y Cultura deba ir acompañada de la firma de algún tipo de acuerdo en el que se establezcan las normas y condiciones pertinentes. Al margen de las cuestiones administrativas, desde nuestro punto de vista estos acuerdos de colaboración deberían incluir algunos elementos técnicos conducentes al mantenimiento de la unidad operativa, como por ejemplo que los futuros usuarios se comprometan a:

- no alterar en ningún caso la estructura de datos de la aplicación, ni su funcionamiento interno, salvo en caso de actualizaciones formalmente establecidas,

- facilitar la consulta e intercambio de sus datos en la misma medida en que participarán de la consulta e intercambio de información del resto de los centros,

- colaborar en el desarrollo de la normalización terminológica, facilitando periódicamente los volcados de índices que se soliciten, aplicando los acuerdos que al respecto se adopten y, en su caso, participando en las comisiones de desarrollo y control que más adelante se mencionan. 
El logro de la máxima efectividad exige que la implantación del sistema en los diversos museos vaya acompañada de una rápida carga de información que permita la puesta en aplicación de sus funcionalidades potenciales. No hay nada más frustrante que tener una aplicación de gestión y que "no funcione" porque al sistema le falta la información necesaria para ser operativa, limitando la rentabilidad del proyecto: envejecimiento de los equipos sin haber amortizado sus prestaciones en caso de lentitud de carga de datos, mal uso del sistema, imagen de ineficacia de la aplicación a falta de la información de base, ...Ni Domus ni ningún otro programa es operativo sin datos, y ningún programa informático crea los datos por sí mismo.

Por ello, los gestores deberán tener muy en cuenta que junto a la compra de máquinas, la instalación de la aplicación, etc, se requiere un programa paralelo de carga de información, mucho más costoso pero vital, que presenta al menos cinco vertientes:

- Volcado de información ya existente en soportes informáticos a las nuevas estructuras catalográficas.

- Grabación de la información consignada en fichas manuales y libros de registro en el sistema informático.

- Inventario y catalogación de aquellos fondos para los que no dispone de estos instrumentos documentales para su posterior grabación en el sistema informático.

- Digitalización de las imágenes existentes en los archivos fotográficos

- Desarrollo de campañas sistemáticas de fotografía digital (en casos particulares también analógica) de fondos.

Esta ardua tarea exigirá un programa de contrataciones temporales o deberá ser confiada a empresas especializadas en tareas documentales, ya que la precariedad general de las plantillas de los centros hacen improbable que puedan hacerse cargo del cometido en plazos razonables.

Tras el establecimiento de una mecánica general de funcionamiento de los procesos, y de una estructura de datos aceptable y aceptada, resulta prioritario el establecimiento de unas sólidas normas de cumplimentación de la información y, sobre todo, de una rígida regulación de la terminología empleada para designar, describir y clasificar los bienes culturales.

Cuando se ve en funcionamiento la aplicación Domus con unos cuantos miles de registros en sus bases de datos, es decir, con el suficiente volumen para que el pantalleo rápido, los listados o la simple memoria de detalles particulares de los objetos, nombre de los coleccionistas, etc, no basten para localizar la información deseada, es cuando se descubre de verdad la necesidad de esta segunda, o tercera, etapa.
Desde el comienzo del proyecto se ha concedido amplia importancia al desarrollo de vocabularios y tesauros que normalicen la terminología empleada en la catalogación y gestión de las colecciones, ya que sólo la unificación terminológica permitirá un intercambio de información fluido y real. Ahora el inicio de la instalación sistemática de la aplicación en los museos, y de la carga de información, hacen urgente el desarrollo de esta tarea para evitar la dispersión y homogeneizar al máximo la consignación de datos en todos los centros.

Con este fin comenzaron a constituirse, en paralelo a la actividad de la Comisión de Normalización Documental, diversos grupos de trabajo especializados: los denominados Grupos de Vocabularios Técnicos, formados por personal técnico de los museos estatales y de otras instituciones especializadas en las diversas temáticas. Aunque con ánimo de ampliar los campos temáticos a medida que avanzaran los trabajos, los grupos iniciales se constituyeron para las siguientes materias: Arte gráfico (Estampa y dibujo), Numismática (Numismática, Sigilografía y Glíptica), Cerámica, Mobiliario, Escultura, Textiles (Tejidos e Indumentaria), Textiles (Encajes y bordados), Metalistería, y Vidrio.

La idea de partida era construir vocabularios que incluyeran tanto denominaciones de objetos, denominaciones de partes o componentes, materias primas, técnicas productivas y decorativas, como términos especializados de descripción, prácticas de medición y otras informaciones básicas para enfrentarse a cada categoría de bienes, y ello haciendo que en la medida de lo posible confluyeran especialistas de diversas áreas (arqueólogos, historiadores del arte, antropólogos, ...) en cada grupo, para hacer más inclusivos los acuerdos, y haciendo que todos los equipos trabajaran sobre una base de datos de estructura común de modo que posteriormente pudieran irse conjuntando y articulando los vocabularios generados por cada uno de los Grupos.

Por diversas razones, entre ellas el escaso apoyo administrativo a una tarea no remunerada de manera específica, los grupos fueron dejando de funcionar en etapas diversas de su trabajo, y sólo llegó a publicarse el primero de los vocabularios (Blas Nenito, 1996). Deberán buscarse los medios para reactivar su operatividad, y para aumentar el número de áreas temáticas, ya que su existencia comienza a resultar urgente.

Y complementando esta tarea de los vocabularios especializados por áreas temáticas, resulta necesario el establecimiento o adopción de tesauros y tablas de carácter general (y sus grupos de trabajo respectivos), tales como:

- Tesauro de materias primas

- Tesauro de técnicas y procedimientos de fabricación

- Tesauro de términos geográficos 
- Tesauro iconográfico

- Tesauro de contextos culturales (incluyendo períodos geológicos e históricos, estilos artísticos y grupos culturales)

- Tesauro de clasificaciones temáticas

Tarea en la que no podemos olvidar la necesidad de aunar esfuerzos con otras instituciones que trabajan en la misma vía, y en particular con el Instituto Andaluz de Patrimonio Histórico, impulsor del Tesauro de Patrimonio Histórico Andaluz, cuyo desarrollo deseamos que no se detenga para que pueda ser llegar a ser una herramienta básica en esta lucha común por la normalización terminológica.

De hecho, la tarea terminológica no puede ser una tarea individual, no podrá darse por concluida en un breve plazo, y requerirá un constante esfuerzo y colaboración de todos los centros participantes en el proyecto, colaboración que deberá vehicularse a través de una comisión de control terminológico, con técnicos y documentalistas que periódicamente revisen la terminología utilizada en el conjunto del sistema, actualicen el contenido de los tesauros, etc.

Una posible estrategia es la constitución, bajo esa comisión de control, de comisiones sectoriales que se ocupen del desarrollo y mantenimiento de la base léxica necesaria para los diversos epígrafes del sistema: denominaciones de objetos, materias primas, nombres de autores, identificaciones iconográficas, etc. Con la periodicidad que se establezca cada museo remitirá los índices correspondientes a cada comisión; las comisiones valorarán la pertinencia de los términos utilizados en cada centro, sea para introducirlos en el tesauro o listado correspondiente si se acepta su uso, sea para rechazarlos o plantear alternativas en caso contrario; y a continuación devolverán el índice actualizado y unificado a todas las instituciones, con las instrucciones pertinentes para actualizar la información de las bases de datos.
La extensión del empleo de la aplicación al mayor número de instituciones posible ampliará, por una parte, el volumen de datos sobre los que trabajar para la normalización terminológica, pero también el número de técnicos potencialmente colaboradores en las tareas de revisión y actualización de los instrumentos documentales.

Domus es una aplicación informática de gestión de museos. Supongo que la participación en su creación me impide decir una más, pero evidentemente no es la única, ni quizás sea la mejor: tanto en España como en otros países se han desarrollado en los últimos años otros modelos (véase, por ejemplo, http://www.mda.org.uk/software.htm para diversos paquetes informáticos -anglosajones casi todos, claro está- de catalogación y gestión museográfica). Pero Domus es una aplicación accesible a la práctica totalidad de los museos españoles; previsiblemente será una aplicación que tendrá el apoyo de diversas administraciones públicas en los años que vienen, lo que facilitará sus mejoras y ampliaciones; y la entidad de muchas de las instituciones que ya la emplean, o la emplearán en breve, supone una garantía.

Retomando frases del comienzo del artículo, quizás podemos insistir en conservar nuestras manías institucionales, al margen de procedimientos normalizados, y empeñarnos en hacer firmar seis formularios a cada solicitante de un préstamo, o en mantener boletines de desplazamiento interno de fondos que incluyan la firma de diez o doce responsables, pero debemos intentar restringir este tratamiento para nosotros mismos o unos pocos investigadores y colegas a nuestro alrededor. No podemos eludir la responsabilidad de que somos gestores de Patrimonio Cultural y de que los museos son un servicio público; $y$, desde el punto de vista que nos interesa en este momento, no podemos darle la espalda al hecho de que la información que guardan los museos comienza a ser tan apreciada como los propios bienes culturales, y es responsabilidad nuestra hacerla accesible.

\section{Bibliografía}

BLAS BENITO, Javier (coord.). Diccionario del dibujo y la estampa (Vocabulario y tesauro sobre las artes del dibujo, grabado, litografía y serigrafía). Madrid. Calcografía Nacional. 1996. 212 p.

CARRETERO PÉREZ, Andrés. La documentación en el museo: una visión general. Museo, II, 1997, p. I I-29 (Actas de las II Jornadas de Museología "El museo: centro de documentación". Madrid, 1996)

CARRETERO PÉREZ, Andrés. Museos, documentación y nuevas tecnologías: una reflexión sobre la gestión de la información en los museos", pp. 17-27 en Iglesias Gil, José Manuel (ed.), Cursos sobre el Patrimonio Histórico 3 (Actas de los IX Cursos Monográficos sobre el Patrimonio Histórico (Reinosa, julioagosto 1998). Santander. Universidad de Cantabria - Ayuntamiento de Reinosa. 1999
CARRETERO PÉREZ, Andrés, CHINCHILLA, Marina, BARRACA, Pilar, ADELLAC, M. Dolores, PESQUERA, M. Isabel, y ALQUEZAR, Eva. Normalización documental de museos: elementos para una aplicación informática de gestión museográfica. Madrid. Ministerio de Educción y Cultura. 1996. 560 p.

CIDOC. International Guidelines for Museum Object Information: The CIDOC Information Categories. Paris: International Committe for Documentation of the ICOM, 1995.

GETTY ART HISTORY INFORMATION PROGRAM (AHIP). Categories for the Description of Works of Art. The Paul Getty Fondation, Art History College. 1995.

GRANT, Alice (ed.). SPECTRUM: The UK Museum Documentation System. Cambridge: MDA, 1994 